\title{
MINIMALLY INVASIVE OPEN THYROIDECTOMY IN THYROID CANCER WITH COEXISTENT HASHIMOTO THYROIDITIS
}

\author{
Rumen Nenkov, Radoslav Radev, Borislav Petrov, Nikolay Cvetkov, Anatoli \\ Semkov, Katerina Marinova, Nedyalko Nedyalkov \\ Department of Thoracic surgery, UMHAT "St. Marina", \\ Clinic of Thoracic Surgery, UMHAT "St. Marina", \\ Medical University of Varna, Bulgaria.
}

\begin{abstract}
:
One of the minimally invasive thyroidectomy challenges is the application of this technique in the surgical treatment of thyroid cancer. The use of minimally invasive open approach in co-existence of thyroid cancer with Hashimoto thyroiditis is well known provocation to the skills of the surgeon working in the field of thyroid surgery.

Aim: To report our results and to present the possibilities of minimally invasive open approach in the surgical treatment of thyroid carcinoma and coexistent Hashimoto thyroiditis.

Patients and methods: For the period from 2008 to 2011, 641 patients were operated on in our clinic using minimally invasive open approach. In 32 of these patients presence of Hashimoto thyroiditis was found in combination with thyroid cancer. All patients were females, 26 to 46 years age. Patients were selected according to designed and accepted for our institution criteria. The procedures were performed using ultrasound (harmonic) shears (Harmonic Focus ${ }^{\circledR}$ and Harmonic Ace ${ }^{\circledR}$, Ethicon Endo-Surgery). The operative time, incidence, type and severity of complications, length of hospital stay, safety and reliability of the surgical procedure were analyzed.

Results: The operative incision length in all cases was between $2.0-2.5 \mathrm{~cm}$. In 27 patients papillary thyroid carcinoma and in 5 patients - follicular variant of the neoplasm were found. The tumor size ranged between 0.5 and $1.5 \mathrm{~cm}$. In all patients total thyroidectomy using harmonic scalpel was performed. Lymph node metastases in the central neck compartment were not found in any of the cases. The rate, type and severity of complications did not exceed those for patients who underwent conventional thyroidectomy. All patients leaved the hospital in the first 24 postoperative hours. The follow-up did not reveal remnant thyroid tissue in thyroid
\end{abstract}

gland bed or recurrence of the disease.

Conclusions: Our results demonstrate the feasibility and reliability of minimally invasive open approach with harmonic scalpel in the surgical treatment of carefully selected patients with non-advanced thyroid cancer and coexistent Hashimoto thyroiditis

Key words: minimally invasive open thyroidectomy, harmonic scalpel, thyroid cancer, Hashimoto thyroiditis.

The application of minimally invasive approach in the surgical treatment of papillary thyroid carcinoma is one of the challenges for these techniques [1]. Several authors have reported in recent years their results, undoubtedly demonstrating that the minimally invasive approach does not draw back to the conventional technique in the treatment of thyroid cancer if well defined selection criteria are followed $[2,3]$. In our practice, we have used minimally invasive techniques in both patients groups: those with Hashimoto thyroiditis as well as those with papillary thyroid cancer [4, 5]. This study presents our experience with the possibilities of the minimally invasive open approach in the surgical treatment of thyroid carcinoma combined with coexistent Hashimoto thyroiditis.

\section{MATERIALS AND METHODS}

For the period from 2008 to 2011, 641 patients underwent surgery in our institution using minimally invasive open approach and in 32 of these patients thyroid cancer with coexistent Hashimoto thyroiditis have been found. All patients were females, at the age from 26 to 46 years. The patients were selected according to developed and accepted in our clinic selection criteria (Table 1). 
Table 1. Indications for surgical treatment through minimally invasive open approach.

\begin{tabular}{|c|l|}
\hline & INDICATIONS FOR SURGICAL TREATMENT THROUGH MINIMALLY INVASIVE OPEN APPROACH \\
\hline 1. & SOLITARY THYROID NODULES UNDER $3.5 \mathrm{~cm}$ IN SIZE \\
\hline 2. & THYROID GLAND VOLUME LESS THAN 25ml \\
\hline 3. & MULTINODULAR GOITER WITH THE BOTH CRITERIA ABOVE \\
\hline 4. & GRAVES DISEASE, FIRST RECURRENCE \\
\hline 5. & NODULAR FORM OF HASHIMOTO THYROIDITIS \\
\hline 6. & THYROID CANCER (T1NOMo) OR INCIDENTALOMA \\
\hline 7. & THYROID CANCER (T1NOMo) WITH COEXISTENT HASHIMOTO THYROIDITIS \\
\hline
\end{tabular}

The procedure was performed using harmonic scalpel device Focus (Ethicon EndoSurgery Care ${ }^{\mathrm{TM}}$ )(Fig.1).

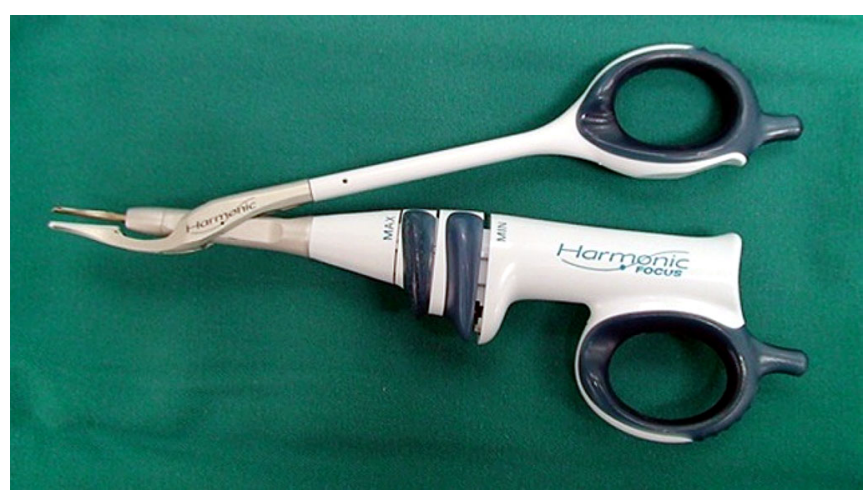

The operative incision length, extent of resection, histological result, operative time, postoperative complications, length of hospital stay, radicality and efficacy of the surgical procedure as well as the cosmetic results were examined.

\section{RESULTS}

The lenth of operative incision in all operated on was between 2.0 and $2.5 \mathrm{~cm}$. In 27 patients papillary thyroid carcinoma and in 5 patients follicular variant of papillary thyroid carcinoma were found with coexistent Hashimoto thyroiditis in all 32 patients. The size of the neoplasms varied in the range $0.5-1.5 \mathrm{~cm}$. Multifocal malignancy wws detected in 7 patients $/ 21,9 \% /$. In all patients total thyroidectomy was performed, using harmonic scalpel (Fig.2).

Fig. 1. Harmonic scalpel device Focus, used in minimally invasive open thyroidectomy.
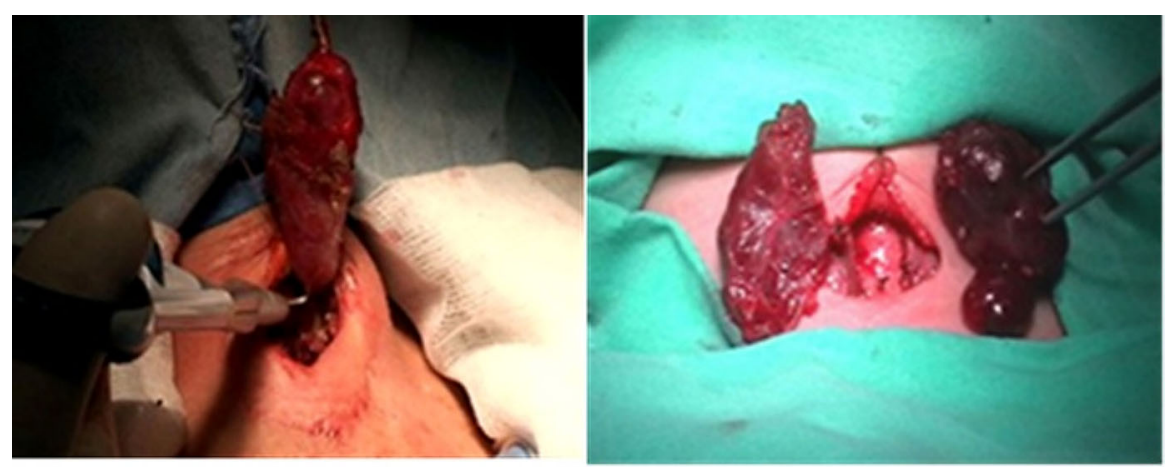

Fig. 2. Total thyroidectomy with harmonic scalpel in patients with thyroid carcinoma combined with Hashimoto thyroiditis.

Hemostatic instruments and vessel ligatures have not been used. Lymph node metastases in the central and lateral neck compertments were not found. In the first three cases $19,4 \%$ / the procedure was finished by placing two passive drainages; in two $/ 6,2 \% /$ patients - by one passive drainage and in all remaining $27 / 84,4 \%$ / patients the procedure was finished without draining.

Transient postoperative hypocalcaemia was detected in 1 patient $/ 3,1 \% /$. There was no surgical injury of the recurrent laryngeal nerve observed in this patients group. All patients were discharged from the hospital in the first 24 hours after surgery. The postoperative follow-up did not found remnant thyroid tissue in the thyroid bed. All patients described the cosmetic result as excellent or very good (Fig.3) 


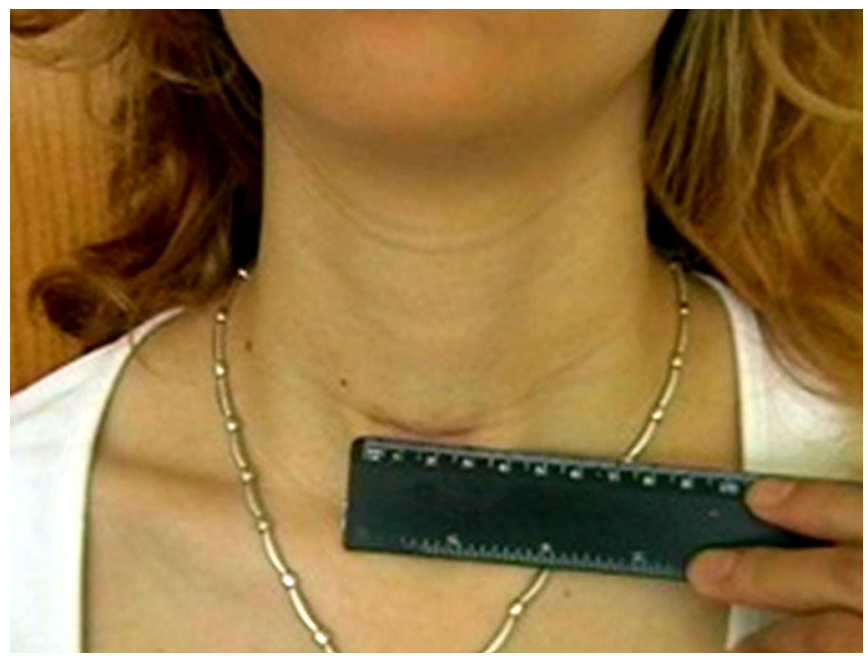

Fig. 3. Cosmetic results after total thyroidectomy throgh minimally invasive open approach for thyroid cancer and coexistent Hashimoto thyroiditis.

\section{DISCUSSIONS}

The minimally invasive methods in thyroid surgery were first developed and introduced in the surgical treatment of solitary thyroid nodules under $3 \mathrm{~cm}$ in size $[6,7,8,9]$. Gradually, the indications for these techniques were extended and included multinodular goiter and even early stage thyroid cancer in patients with thyroid gland volume not exceeding $25 \mathrm{ml}[10,11,12]$.

Hashimoto thyroiditis is the most common cause of hypothyroidism with sevenfold higher incidence in women than in men. The papillary thyroid cancer has two to fivefold higher incidence in women. The probability to develop thyroid carcinoma is $30 \%$ higher in women with Hashimoto thyroiditis than in those without thyroiditis [13]. The high incidence of both diseases, especially in women, gave us the reason to explore the possibilities to apply minimally invasive open approach in situations when the thyroid cancer is combined with Hashimoto thyroiditis.

The main selection criteria for minimally invasive open approach in this group of patients were: small size thyroid carcinoma, usually foun accidentally during thyroid ultrasonography; confirmed after FNAB suspicious thyroid nodule; lack of detectable lymph node metastases; thyroid gland volume under $25 \mathrm{ml}$.

The harmonic scalpel use permits to perform total thyroidectomy without need of hemostatic instruments and ligatures wich makes possible to minimize the length of operative incision.

Meanwhile, the harmonic scalpel gives better opportunities for anatomic exploration of both thyroid lobes and reduces the probability to remaine thyroid remnants, improves the possibility to detect and preserve the parathyroid glands. The reliable and accurate hemostasis achieved by the harmonic scalpel use permits to avoid draining. Drainages were placed at the end of the first three procedures in the beginning of our experience with the technique and only in two other patients with high risk of bleeding.

The lack of complications as well as the minimized tissue trauma during the minimally invasive thyroidectomy gave us the opportunity to discharge all patients until the second postoperative day.

Postoperative thyroid scintigraphy scans were performed in all patients who underwent minimally invasive thyroidectomy for thyroid cancer and they didn't found any thyroid remnant or neck lymph node metastases.

\section{CONCLUSIONS}

Our results demonstrate that when the patient selection criteria are strictly followed, the minimally invasive open approach with harmonic scalpel use is a feasible and valuable option even in the surgical treatment of early stage thyroid cancer with coexistent Hashimoto thyroiditis.

\section{REFERENCES:}

1. Terris DJ. Effect of video-assisted thyroidectomy on the risk of early postthyroidectomy voice and swallowing symptoms. World J Surg. 2008 May;32(5):701. [PubMed] [CrossRef]

2. Miccoli P, Pinchera A, Materazzi G, Biagini A, Berti P, Faviana P, et al. Surgical Treatment of Low- and Intermediate-Risk Papillary Thyroid Cancer with Minimally Invasive VideoAssisted Thyroidectomy. $J$ Clin Endocrinol Metab. 2009 May; 94(5):
1618-1622. [PubMed] [CrossRef]

3. Del Rio P, Sommaruga L, Pisani P, Palladino S, Arcuri MF, Franceschin M, et al. Minimally invasive videoassisted thyroidectomy in differentiated thyroid cancer: a 1-year follow-up. Surg Laparosc Endosc Percutan Tech. 2009 Aug;19(4):290-2. [PubMed] [CrossRef]

4. Nenkov R, Radev R, Hristozov K. Potentiality of minimally invasive open approach with harmonic scalpel in the surgical treatment of thyroid carcinoma. Endocrine journal. 57: s464s464 suppl. 2 mar 2010

5. Nenkov R, Radev R, Bulqshky D, Cvetkov N, Semkov A, Marinova K, et al. Videoasisted Thyroidectomy for thyroid cancer. XVII National Congress of Surgery - Varna, 11-14 October 2012. Abstract book page. 557-564. [in Bulgarian] .

6. Miccoli P, Berti P, Conte M, Bendinelli C, Marcocci C. Minimally invasive surgery for thyroid small nodules: preliminary report. $J$ 
Endocrinol Invest. 1999 Dec;22(11): 849-851. [PubMed]

7. Shimizu K, Akira S, Jasmi AY, Kitamura Y, Kitagawa W, Akasu H, et al. Video-assisted neck surgery: endoscopic resection of thyroid tumors with a very minimal neck wound. J Am Coll Surg. 1999 Jun; 188(6):697-703. [PubMed]

8. Bellantone R, Lombardi CP, Raffaelli M, Rubino F, Boscherini M, Perilli W. Minimally invasive, totally gasless video-assisted thyroid lobectomy. Am J Surg. 1999 Apr; 177(4):342-3. [PubMed]
9. Park CS, Chung WY, Chang HS. Minimally invasive open thyroidectomy. Surg Today. 2001; 31(8): 665-9. [PubMed]

10. Miccoli P, Elisei R, Materazzi G, Capezzone M, Galleri D, Pacini F, et al. Minimally invasive video-assisted thyroidectomy for papillary carcinoma: a prospective study of its completeness. Surgery. 2002 Dec;132(6):10703. [PubMed] [CrossRef]

11. Bellantone R, Lombardi CP, Raffaelli M, Alesina PF, De Crea C, Traini E, et al. Video-assisted thyroidectomy for papillary thyroid carcinoma.
Surg Endosc. 2003 Oct;17(10):1604-8. [PubMed] [CrossRef]

12. Ikeda Y, Takami H, Sasaki Y, Takayama J, Kan S, Niimi M. Minimally invasive video-assisted thyroidectomy and lymphadenectomy for micropapillary carcinoma of the thyroid. $J$ Surg Oncol. 2002 Aug;80(4):218-221. [PubMed] [CrossRef]

13. Repplinger D, Bargren A, Zhang YW, Adler J, Haymart M, Chen H. Is Hashimoto's thyroiditis a risk factor for papillary thyroid cancer?. J Surg Research. 2008 Nov;150(1):49-52. [CrossRef]

Address for correspondence:

Rumen Nenkov M.D., PhD

Clinic of Thoracic Surgery, UMHAT "St. Marina”, Varna

Medical University "Prof. Paraskev Stoyanov", Varna

1, Hristo Smirnenski str., Varna, Bulgaria

E-mail: nenkovrn@hotmail.com; 